\title{
Telemedicine and ethics: opportunities in India
}

\author{
JITENDER ANEJA, SONAM ARORA
}

\begin{abstract}
Prior to the Covid-19 pandemic, telemedicine was an upcoming modality of diagnosis and treatment, but was limited by inadequate guidelines and legislation. Now, during the pandemic, policy makers worldwide have found it prudent to set forth new telemedicine guidelines to ease and regulate operations. The Government of India, along with the Board of Governors (in supercession of the Medical Council of India), amended the Indian Medical Council Act, 1956, and published the Telemedicine Practice Guidelines in 2020 to lay down a framework for telemedicine practice in our country. This step will provide a medico-legal context for the delivery of online health services. However, the Guidelines in their present form only partly address the ethical aspects of telemedicine in India. Here, we briefly describe these Guidelines and highlight the ethical concerns surrounding the teleconsultation process in our country. We also suggest possible solutions to these ethical issues surrounding the practice of telemedicine.
\end{abstract}

Keywords: Telemedicine, guidelines, India, ethics

\section{Introduction}

Telemedicine is still a nascent field in India, even though it started in 2001, by way of the telemedicine pilot project by the Indian Space Research Organisation (ISRO), which linked Chennai's Apollo Hospital with its rural counterpart in Aragonda village, in the Chittoor district of Andhra Pradesh (1). Since then, many institutes have introduced telemedicine services, notably the telepsychiatry services provided by the Postgraduate Institute of Medical Education and Research, Chandigarh, which developed a computerised diagnostic support system to standardise the diagnosis and

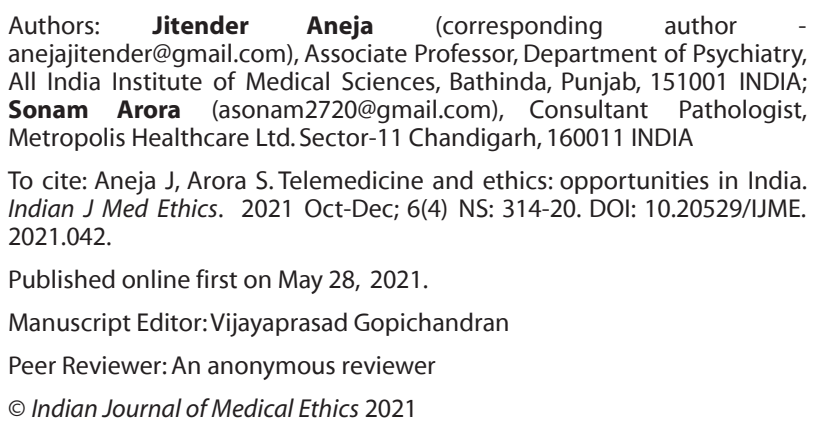

Published online first on May 28, 2021.

Manuscript Editor:Vijayaprasad Gopichandran

Peer Reviewer: An anonymous reviewer

c Indian Journal of Medical Ethics 2021

management of psychiatric disorders (2), and the National Institute of Mental Health and Neurosciences' use of Project ECHO (Extension for Community Healthcare Outcomes, developed in New Mexico) to train tobacco cessation counsellors and manage addictive disorders (3).

However, these initiatives were unable to bridge the gap between researchers' views on the importance of telemedicine and its actual utilisation in India. Insufficient resources, tardy policymaking at the national as well as state levels, poor acceptance among patients as well as medical professionals, and unresolved medico-legal issues, all contribute to this situation (4). The confounding state of the Indian laws applicable to telemedicine, which govern both the medical profession and information technology - the Drugs and Cosmetics Act, 1940; the Indian Medical Council Act, 1956; the Information Technology Act, 2000 (IT Act); the Clinical Establishments (Registration and Regulation) Act, 2010; and the Information Technology (Reasonable Security Practices and Procedures and Sensitive Personal Data or Information) Rules, 2011 - is an additional factor (5).

Telemedicine received an impetus recently with the advent of the novel coronavirus disease 2019, or Covid-19. In response to the pandemic, the Board of Governors which has superseded the Medical Council of India (MCl) amended the Medical Council Act, 1956 (102 of 1956), and published the Telemedicine Practice Guidelines as part of the Indian Medical Council (Professional Conduct, Etiquette and Ethics) Regulations of 2020 ('Guidelines' hereafter). The Government of India (Gol) subsequently notified these Guidelines with effect from May 12, 2020 (6).

This long-awaited amendment aims to provide easy access to affordable healthcare:

The purpose of these guidelines is to give practical advice to doctors so that all services and models of care used by doctors and health workers are encouraged to consider the use of telemedicine as a part of normal practice. These guidelines will assist the medical practitioner in pursuing $a$ sound course of action to provide effective and safe medical care founded on current information, available resources, and patient needs to ensure patient and provider safety (6: $p$ 8).

Second, the Guidelines provide a definition of "telemedicine", the same as that of the World Health Organization (WHO): 
The delivery of healthcare services, where distance is a critical factor, by all healthcare professionals using information and communication technologies for the exchange of valid information for diagnosis, treatment and prevention of disease and injuries, research and evaluation, and for the continuing education of healthcare providers, all in the interest of advancing the health of individuals and their communities (7).

The Guidelines also provide definitions of "Telehealth" and "registered medical practitioner" (RMP)(6). "Telehealth" is defined as the "delivery and facilitation of health and healthrelated services including medical care, provider and patient education, health information services, and self-care via telecommunications and digital communication technologies" (8). In comparison to telemedicine, telehealth is a broader term and encompasses the consultations and the digital technology used for teleconsultations. The Guidelines define a "registered medical practitioner" as "a person who is enrolled in the State Medical Register of the Indian Medical Register under the Indian Medical Council Act 1956" (9). The Guidelines also lay out the protocols for providing telehealth services to the community, under various sections and subsections.

In this discussion, we highlight some of the major ethical concerns that the Guidelines touch upon, but do not fully cover. We also propose possible solutions to these ethical concerns and recommend a revised Telemedicine Act or Rules.

\section{Informed consent}

Though the concept of informed consent is well established, the sharp rise in digitisation mandates an updating of this concept. In the traditional form of consent, the medical professional discloses the relevant information about an investigation, treatment, or new research drug/intervention (for clinical trials) and discusses this with the patient face-toface (10). The patient is expected to take an informed decision after properly understanding the available choices, and either grant consent to or refuse it. Telemedicine requires a few other considerations in addition to changes in the clinical aspects of consultations.

We highlight a key medico-legal case pertaining to telemedicine. In 2005, Dr Christian Hageseth, a psychiatrist, provided a prescription of fluoxetine (an antidepressant) over the internet to a patient who consulted him from the state of California, USA. Unfortunately, the patient committed suicide a month after the teleconsultation. The online teleconsultation company operated from outside the USA, but $\mathrm{Dr}$ Hageseth was licensed only to practise in the state of Colorado, USA. In the absence of a record of patient consent, Dr Hageseth was sentenced to nine months in prison because he was not licensed to practise in the state of California $(11,12)$. It is however very difficult to predict an altered course of action even with recorded informed consent.

\section{When and how to seek informed consent}

Obtaining informed consent from patients safeguards their rights. This also protects the doctor from any future litigation and accusations of a breach of patients' rights. The Guidelines recommend seeking and recording consent prior to provision of a medical consultation (6). In the case of patient-initiated consult, implied consent is considered valid. However, the RMP is advised to seek explicit consent. The Guidelines also hold the medico-legal value of informed consent in a teleconsult on par with that in a face-to-face consultation. They also endorse the view that it is the prerogative of the RMP to decide between the provision of teleconsult or a faceto-face consult. The RMP may also close a teleconsultation if a face-to-face consult is deemed to be necessary such as in cases of emergency.

Until now, in routine clinical practice, the patient's consent is "implied" because the patient visits and consults a doctor. The same concept of "implied consent" can be applied to the teleconsultation format, according to the Guidelines. At the All India Institute of Medical Sciences, Bathinda, where we provide telemedicine services, we seek oral consent from the patient before providing a consultation, but we do not record a video of the consent. Third-party platforms providing teleconsultation services to patients do get explicit consent, by requiring patients to mark a checkbox signifying agreement with the terms and conditions of services. However, this may not meet ethical requirements as the patient might not have completely understood the concept of teleconsultation or, subsequently, the treatment advised (13). Although Kotsopoulu et al have suggested that consent can be written or verbal depending upon the circumstances, recording the granting of consent, or the insertion of an electronic patient consent form, may be prudent and beneficial for doctors as well as patients (14).

\section{Informed consent in the case of reference to another RMP}

A grey area remains in the case of teleconsultation initiated by an RMP, as a referral to another RMP or specialist. The patient may have provided consent for treatment by only the primary RMP. For this reason, unless the patient gives consent to the referred service, the primary RMP performing a procedure following a referred consultation may be violating a boundary. Ben Stanberry has written authoritatively on this aspect of telemedicine as well as other related medico-legal and ethical issues (15). He highlights the issue of remotely performing an invasive procedure, especially pertaining to seafarers, who may at times need otherwise inaccessible specialist services. The current Guidelines bar RMPs from performing any surgical or invasive procedure remotely through the use of digital technology. We feel that the suggestion from a remote RMP, eg a psychiatrist, for another physically present RMP to provide an injectable medicine, such as an antipsychotic, may save a patient's life in certain emergencies. However, this will be considered to be professional misconduct, and a breach of the patient's 
privacy, if it is performed without explicit consent.

\section{Information and communication technology and informed consent in telemedicine}

Electronic or digital informed consent implies that the patient has read and comprehended all the information provided online, including that pertaining to the maintenance of electronic records, their encryption and de-identification, etc. Kaplan and Litewka point out what actually should constitute informed consent in telemedicine (16). They acknowledge the common ethical concerns of privacy, security, information accuracy, and confidentiality. They also suggest that the involvement of new technologies would entail new and hidden risks; giving consent in such a scenario implies also consenting to these unseen risks, including those that are emotional or psychological.

There must also be ways to deal with problems associated with the lack of face-to-face interaction inherent in certain forms of electronic communication (eg, email, chat). Schairer et al refer to the commercial terms of use, as well as privacy policies, pertinent to the informed consent process (17). The informed consent that some telehealth platforms and mobile health systems seek is similar to what online consumer services (banking, online shopping) request in microscopic print. Patients often tick the box without actually first obtaining the necessary information or having a clear understanding of what is involved.

Second, patient data must be protected from data mining. A few countries have established laws which guide the process of collecting and disseminating health-related data, such as the Health Insurance Portability and Accountability Act of 1996 (HIPAA) in the USA, or the Data Protection Act (2018) of the UK which the National Health Service uses.

In India, telemedicine is partly guided by the IT Act and Rules. These require third parties to protect, secure and maintain patients' medical history and records. This includes sensitive data such as information on physical, physiological and mental health conditions, and sexual orientation. However, while such instances are referred to, the complete definition of sensitive data is not given. Moreover, certain provisions of the Act override other provisions. For example, if a case of negligence is filed against an RMP who provided telemedicine services, the IT company involved as an intermediary may not be liable under the rules regulating the practice of medicine, despite being a beneficiary in such transactions. Similarly, various online pharmacies in India are regulated not under the Drugs and Cosmetics Act 1940, but under the IT Act 2000. Another major lacuna is that the Act excludes government offices from its purview.

To allay these apprehensions, the Supreme Court of India held that the right to privacy is a fundamental right protected under Article 21 of the Indian Constitution in the Puttaswamy judgment in 2017 (18). Consequently, in 2018, the Gol put forward the Personal Data Protection Bill, which is still under review by a Parliamentary Standing Committee.

In addition, the Gol has also constituted a National Health Authority in order to build the IT infrastructure in the health sector, so that all stakeholders could be brought under its regulatory domain. In his 2020 Independence Day speech, the Prime Minister launched the National Digital Health Mission as a pilot project in five union territories. It is hoped that this ambitious project will bring the Indian health delivery sector on par with some of the best-developed health sectors in the world, and open new avenues in teleconsultation.

\section{The format of informed consent in telemedicine}

Shore provides a framework for seeking informed consent in the field of telepsychiatry which emphasises not just the provision of a psychiatric consultation but also helping the patient to understand the whole process of teleconsultation, including confidentiality, any logistical issues that may arise, and the alternatives available (19). He also provides a useful video teaching guide for the process of taking informed consent (See: http://www.youtube.com/watch? v=zWBJDj9owv0\&feature=youtu.be).

Along the same lines, some researchers have developed electronic modules for seeking informed consent for teleconsultations, as well as for participation in clinical research trials, eg the MyHeart Counts study application (20, 21). Researchers at Yale University in the US have developed an interactive virtual tool to seek informed consent. This uses multimedia elements to educate the patient, thereby enhancing their understanding of the process of informed consent (22). Gioia and Salducci recommend that any attempt to seek informed consent must indicate what data are being collected, the objective and method of treatment, the subjects with whom data may be shared, identifying who will hold such data, as well as the methods used to protect the data (23). Similar views are presented by Tilda Cvrkel, who makes the following recommendations for a good quality consent process (24):

a. Deliver information using at least two of the methods written, video, or live conversation.

b. Use simple language to explain the process of data collection and storage.

c. Specify the risk of potential data breaches (or of the data becoming public), using neutral phrasing.

d. Discuss unexpected consequences, findings, or research possibilities.

e. Provide the option to withdraw consent and retrieve personal data.

f. Explain the ownership and accessibility of data, and any profit agreements.

We also recommend that it be made mandatory to seek 
informed consent prior to the start of every case of teleconsultation. The method of seeking this consent may vary between teleconsultation set-ups.

\section{Telemedicine and patient autonomy}

There are two components of telemedicine with different implications for patient autonomy. In the first, the patient is monitored by means of smart wearable sensors, which are commonly used for self-monitoring, and accessed remotely by a team of health professionals. In the other, the patient seeks one-time medical help.

The first case is beyond the scope of this paper, as this has not been discussed in the Guidelines. In the second case, we may assume that the process of a teleconsultation starts with due respect for the autonomy of the patient (the end user). On one hand, the patient has the liberty to choose the healthcare set-up; on the other, the RMP may work to build a good doctor-patient relationship by providing a personal dimension of care through video consultations. Some authors report that both doctors and their patients value face-to-face consultations more highly (25). We have also observed this in our current practice of telemedicine during the pandemic.

We can strengthen the autonomy of patients by increasing their health literacy. It is a complex issue, and sceptics have raised doubts about the level of medical knowledge that should be shared with patients. We suggest that, particularly in the context of telemedicine and telehealth, engaging patients in their own care supports their autonomy.

\section{Standards of care}

The Guidelines recommend a standard of care on par with face-to-face consultations for telemedicine services. The standard of care mainly focusses on litigation where a point of dispute is whether the standard of care was followed, for which reason certain governments have passed legislation on this. For example, the state of Washington in the US proclaims that the standard of care is not met when "the defendant or defendants [fail] to exercise that degree of skill, care and learning possessed by other persons in the same profession..." (26).

With respect to telemedicine, standard of care would depend upon the specialty of the physician and the mode of communication. Certain clinical specialties such as surgery or orthopaedics require physical examination or investigations to arrive at a diagnosis. Here, telemedicine on an audio call or even videoconferencing may not be suitable. The current Guidelines only permit doctors to provide counselling, prescribe a selected list of drugs, and suggest first aid. An RMP should identify an emergency condition, advise first aid, and then refer the patient to a provider who can take this forward. It is up to the physician to judge what constitutes an emergency. However, poor judgement in such scenarios has been harshly punished in the past, such as in the case of Deepa Sanjeev Pawaskar and Anr vs the State of Maharashtra, 2018 (27). The field of medicine is so subjective that the judgement of one physician may not be same as that of another, and often a serious complication may be overlooked as a common adverse effect.

Another aspect of care is its continuity. The Guidelines recommend that when an RMP deems a face-to-face consult necessary, the physician must ask the patient to visit a doctor in person. We believe that for continuity of care, the RMP/ telemedicine team must have a collaborative system in place to refer a patient to a centre where a physician can communicate and share relevant health information with them. The National Digital Health Mission of India envisages a paradigm wherein generating a unique health identity card will ensure this. Extraordinary efforts, research, and practice will be needed from both policymakers and those executing this digital innovation. Each specialty must also publish its own guidelines of practice and seek approval by the Gol so as to establish a standard format across the country.

\section{The doctor-patient relationship}

A good doctor-patient relationship is necessary for patients' satisfaction, their understanding of their health condition, their compliance with treatment, the outcome of the treatment, and even their psychological well-being (28). These factors in turn are often influenced by the medium of consultation. Some authors feel that telemedicine technology in healthcare will lead to a reduction of the humane qualities of this profession, leading to depersonalised healthcare (29).

However, a few experts believe that some specific groups of patients, such as those seeing psychiatrists, may feel less inhibited, stigmatised, and intimidated in teleconsultations in comparison to face-to-face consultations, which would better facilitate their care (30). Either way, doctors must now be trained to seek medical information from the patient along with providing a comfortable and warm environment with minimal distractions during the process of teleconsultation. Two more aspects of a face-to-face consultation which are lost in telemedicine are the non-verbal behaviour of the patient (both physical and emotional), and touch. These might be of considerable importance in certain branches of medicine, such as psychiatry, where the diagnosis is often based upon the non-verbal behaviour and affective responses of the patient (31).

The doctor-patient relationship may also be influenced during consultation between one RMP and another. On one hand, the primary practitioner (nurse or RMP) may supplement medical information, provide findings of a physical examination and non-verbal cues, and coordinate the execution of treatment instructions (32). On the other hand, the relationship between the two professionals may be marred by a range of factors, such as socio-demographic variables, cultural and linguistic backgrounds, variance in the level of medical training, and the specialist consultant's 
keenness to obtain medical information.

Another variable affecting the doctor-patient relationship, which has not been addressed in the Guidelines, is the maintenance of dignity in the encounter. We have often observed that patients do not follow the expected decorum when seeking a medical consultation through telemedicine. The improper use of language, poor posture, inappropriate clothing, selection of a room that does not limit surrounding disturbances, and violations of boundaries (of a professional relationship) have often led to unpleasant interactions, to an extent seldom seen in formal face-to-face consultations in office or hospital settings. We therefore propose that when expanding the use of telemedicine in our country, the proper training of doctors and other healthcare staff at various levels, as well as patient literacy in this context, are required.

\section{Technical aspects of telemedicine and ethics}

Ackerman and others provide an overview of the process of developing the technology of telemedicine in keeping with the perspectives of various stakeholders, namely patients, practitioners, researchers, providers of healthcare services, professional societies, the healthcare industry, and policymakers (33). We highlight some issues which have so far only been partly addressed (in some form) in the Guidelines and are essential to strengthening the practice of telemedicine in India.

\section{Confidentiality, privacy, and ownership of data}

The need for confidentiality increases in telehealth and telemedicine, as security breaches are a persistent threat. The situation may worsen when the maintenance of personal health records in various digital formats is outsourced to private entities. It may also be impossible in the present scenario to establish a system which is resistant to hacking, or (as some sceptics point out) one that protects the data from governmental surveillance $(34,35)$.

A related issue is the accessibility of the data from the patient's perspective. There are two aspects to this: the ownership of medical records and access to them. Although information provided by patients belongs to them, in some countries, the medical records compiled by a doctor are the RMP's property and not the patient's (34). Some contend that patients may have the right to access their medical records as maintained by the doctor/hospital. However, there is no legislation in India on this contentious subject, although the Ministry of Health and Family Welfare (MoHFW) provides a "Charter of Patient Rights" as enshrined in the Constitution of India.

Examples have been found in the UK, where the Access to Medical Reports Act, 1988, and the Access to Health Records Act, 1990, grant patients access to their teleconsultation records $(15,34)$. The British Medical Association also encourages doctors to provide patients complete access to their medical records except in situations where such records are believed to be deleterious to the patient's health or when they may compromise the confidentiality of other people [also contained in the aforementioned legislations $(15,34)$ ].

The present Guidelines do not offer any input on specifications for hardware or software related to teleconsultations, including infrastructure building and maintenance of records. The only progressive development is that the doctor may not be held responsible for a breach of confidentiality if there is reasonable evidence that the patient's privacy and confidentiality were compromised by a technology breach or by a person other than the doctor.

Legally speaking, even specialists whom the RMP consults for a patient, as well as all the members of the teleconsultation team involved in healthcare, are duty-bound to maintain confidentiality. It has even been argued that information about the patient obtained from other sources, such as medical records or investigation reports, also come under the purview of confidentiality (34).

Another major concern here is the encryption of data which are transmitted (36). In a recent example, the security of a prominent teleconference platform was highlighted by many leading media houses and newspapers in India, leading to a government advisory to avoid using a platform that did not provide end-to-end encryption. However, if encrypted content is already available in the public domain, then its decryption is not considered a breach of privacy and confidentiality, as per various international court rulings in this regard. Meanwhile, though the state provides for privacy under the IT Act 2000, it does not specify safeguards against governmental surveillance. Sceptics have criticised the Aarogya Setu application launched in India during the Covid19 pandemic for its possible breach of the privacy of citizens. These issues are addressed in the Personal Data Protection Bill, 2018, which provides a structural framework for various online consumer services, protection of their data, procedures, requirements of software and hardware, setting up authorities to handle violations, and even giving penalties in such cases.

\section{Recording of teleconsultations}

The Guidelines do not recommend the recording of teleconsultations in India and only suggest the maintenance of call logs. However, they go on to state that besides the prescription shared with the patient, the RMP shall not retain other records, reports, documents, images, diagnostics, data, etc, whether digital or non-digital. Even the telemedicine portal designed by the MoHFW, which is available as eSanjeevani OPD (https://esanjeevaniopd.in/), does not have any provision for the health professional to keep the patient's data. Some professionals and academic and non-academic institutes may be interested in recording teleconsultations or maintaining patient data for the purpose of audits, research, and teaching. 


\section{The design of telemedicine services}

The major ethical issue to be considered is the userfriendliness of the modality of telemedicine. It must be suitable to different environments (home, office) and different populations intending to use the technology (geriatric patients, rural populations).

\section{Miscellaneous}

There are certain other issues in the Guidelines pertaining to the prescription of certain categories of drugs as well as the exclusion of Schedule $X$ drugs from the prescribed list. This means a patient who is, for example, suffering from a terminal illness and experiencing severe pain, or an injectable drug user who is already on opioid substitution therapy from a government-approved centre, cannot employ telemedicine to seek a refill of medications from the category of opioids and other Schedule $\mathrm{X}$ drugs.

Further, although the Insurance Regulatory and Development Authority of India (IRDAI) recently recommended the inclusion of telemedicine in health insurance benefits, the recent Guidelines offer no clarity on this for the doctor or the patient. Currently, no health insurance in India covers telemedicine in terms of litigation, claims, and reimbursements. Moreover, while the Guidelines have made it easier for a family member or guardian to seek teleconsultation for a dependent child or an incapacitated elderly patient, a doctor should exercise care when providing healthcare services in such instances to avoid unnecessary litigation.

\section{Future directives}

The recent efforts by the Board of Governors, in supercession of the $\mathrm{MCl}$, provide an impetus to make adequate health services available to remote, inaccessible, and peripheral areas in times to come. Providing RMPs an online course on telemedicine would assist them in adapting to the concept, obtaining in-depth knowledge, and resolving ethical dilemmas. We may soon see such a course incorporated in undergraduate curricula. However, the predominant emphasis of the Guidelines seems to have been the provision of a legal framework to enable telemedicine to address healthcare issues in the pandemic times.

It is always prudent to have methodologically sound, evidence-based, and ethically appropriate guidelines for the delivery of telemedicine services. We have tried to summarise them in tabular form for better understanding (Table 1). Although the Guidelines in their present form make the provision of services easy for the healthcare provider as well as the seeker of good health, they still need a lot of work to address the various ethical and legal aspects of telemedicine in India.

\section{References}

1. Indian Space Research Organisation. Telemedicine Initiative [Internet]. Telemedicine: healing touch through space - enabling specialty healthcare to the rural and remote population of India.
Bangalore: ISRO; 2005 Feb [cited 2021 Apr 12]. Available from: http:// www.televital.com/downloads/ISRO-Telemedicine-Initiative.pdf.

2. Chakrabarti S. Usefulness of telepsychiatry: a critical evaluation of vidoconferencing-based approaches. World J Psychiatry 2015.5(3):286304. Doi: $10.5498 /$ wjp.v5.i3.286.

3. Chand P, Murthy P, Gupta V, Kandasamy A, Jayarajan D, Sethu L, et al. Technology enhanced learning in addiction mental health: developing a virtual knowledge network - NIMHANS ECHO. In: Proceedings of the IEEE Sixth International Conference on Technology for Education: Clappana; 2014. p. 29-32. Doi: 10.1109/T4E. 2014.14.

4. Gorea RK. Legal aspects of telemedicine: telemedical jurisprudence. JPAFMAT. 2005;5.

5. Ateriya N, Saraf A, Meshram VP, Setia P. Telemedicine and virtual consultation: the Indian perspective. Natl Med J India. 2018;31(4):2158. Doi: 10.4103/0970-258X.258220.

6. Board of Governors in supersession of $\mathrm{MCl}$. Telemedicine Practice Guidelines: Enabling registered medical practitioners to provide healthcare using telemedicine. New Delhi: MoHFW. 2020 Mar 25 [cited 2021 Apr 2]. Available from: https://www.mohfw.gov.in/pdf/ Telemedicine.pdf

7. World Health Organization. Telemedicine: opportunities and developments in member states. 2010 [cited 2021 Apr 12]. Available from: $\quad$ https://apps.who.int/iris/bitstream/handle/ 10665/44497/9789241564144_eng.pdf?sequence $=1$ \&isAllowed $=y$.

8. Tuckson RV, Edmunds M, Hodgkins ML. Telehealth. N Engl J Med. 2017 Oct 19;377(16):1585-92. Doi: 10.1056/NEJMsr1503323.

9. The Indian Medical Council Act, 1956. [cited 2021 Apr 12]. Available from: https://legislative.gov.in/sites/default/files/A1956-102_0.pdf

10. Grady C. Enduring and emerging challenges of informed consent. $N$ Eng J Med. 2015;372(22):2172. Doi: 10.1056/NEJMc1503813.

11. Becker CD, Dandy K, Gaujean M, Fusaro M, Scurlock C. Legal perspectives on telemedicine - part 1:legal and regulatory issues. Perm J. 2019;23:18-293. doi: 10.7812/TPP/18-293.

12. Fields BG. Regulatory, legal and ethical considerations of telemedicine. Sleep Med Clin. 2020 Sep;15(3):409-16. Doi: 10.1016/ j.jsmc.2020.06.004.

13. Recupero PR, Rainey SE. Informed consent to e-therapy. Am J Psychother. 2005;59(4):319-31. Doi: 10.1176/appi.psychotherapy. 2005.59.4.319.

14. Kotsopoulou A, Melis A, Koutsompou VI, Karasarlidou C. E-therapy: the ethics behind the process. Procedia Comp Sci. 2015;65:492-9. Doi: 10.1016/j.procs.2015.09.120.

15. Stanberry B. The legal and ethical aspects of telemedicine. J Telemed Telecare 1998;4:95-7. Doi: 10.1258/1357633981931632.

16. Kaplan B, Litewka S. Ethical challenges of telemedicine and telehealth. Camb Q Healthc Ethics. 2008;17(4):401-16. Doi: 10.1017/ S0963180108080535.

17. Schairer CE, Rubanovich CK, Bloss CS. How could commercial terms of use and privacy policies undermine informed consent in the age of mobile health? AMA J Ethics. 2018; 20(9):E864-72. Doi: 10.1001/ amajethics.2018.864.

18. Supreme Court of India. Justice KS Puttaswamy (Retd) ... vs Union of India And Ors. WPC (Civil) 494 of 2012, August 24, 2017 [cited 2021 May 18]. Available from: https://indiankanoon.org/doc/91938676/.

19. Shore JH. Telepsychiatry: videoconferencing in the delivery of psychiatric care. Am J Psychiatry. 2013;170(3):256-62. Doi: 10.1176/ appi.ajp.2012.12081064.

20. Hershman SG, Bot BM, Shcherbina A, Doerr M, Moayedi Y, Pavlovic A, et al. Physical activity, sleep and cardiovascular health data for 50,000 individuals from the MyHeart Counts study. Sci Data. 2019;6(1):24. Doi: 10.1038/s41597-019-0016-7.

21. Grady C, Cummings SR, Rowbotham MC, McConnell MV, Ashley EA, Kang G. Informed consent. N Eng J Med. 2017;376(9):856-67. Doi: 10.1056/NEJMra1603773.

22. Abujarad F, Alfano S, Bright TJ, Kannoth S, Grant N, Gueble M, et al. Building an informed consent tool starting with the patient: The patient-centered virtual multimedia interactive informed consent (VIC). In AMIA Annual Symposium Proceedings Archive. 2017;374-83.

23. Gioia G, Salducci M. Medical and legal aspects of telemedicine in ophthalmology. Rom J Ophthalmol. 2019;63(3):197-207.

24. Cvrkel T. The ethics of mHealth: moving forward. J Dent. 2018 Jul; 74(S1):S15-S20. Doi: 10.1016/j.jdent.2018.04.024

25. Sabesan S, Allen D, Caldwell P, Loh PK, Komesaroff P, Talman M, et al. Practical aspects of telehealth: doctor-patient relationship and communication. Int Med J. 2014;44(1):101-3. Doi: 10.1111/imj.12323.

26. Moffet P, Moore G. The standard of care: legal history and definition the bad and good news. West J Emerg Med. 2011;12(1):109-12.

27. High Court of Bombay. Deepa Sanjeev Pawaskar and Anr vs the State of 
Maharashtra. Criminal Anticipatory Bail Application No. 513 of 2018 [cited 2021 April 12]. Available from: https://indiankanoon.org/doc/ $160266477 /$.

28. Miller EA. Telemedicine and doctor-patient communication: a theoretical framework for evaluation. J Telemed Telecare. 2002;8(6): 311-8. Doi: 10.1258/135763302320939185.

29. Evans HH. High tech vs 'high touch': the impact of medical technology on patient care. In: Clair JM, Allman RM, editors. Sociomedical perspectives on patient care. Kentucky, MA: University Press of Kentucky; 1993. p. 83-95.

30. McLaren P, Ball CJ, Summerfield AB, Watson JP, Lipsedge M. An evaluation of the use of interactive television in an acute psychiatric service. J Telemed Telecar. 1995;1(2):79-85. Doi: 10.1177/1357633X9500100203.

31. Miller EA. The technical and interpersonal aspects of telemedicine: effects on doctor-patient communication. J Telemed Telecare. 2003;9:1-7. Doi: 10.1258/135763303321159611

32. Gelber $H$, Alexander $M$. An evaluation of an Australian videoconferencing project for child and adolescent telepsychiatry. $J$ Telemed Telecare. 1999:5(S1):21-3. Doi: 10.1258/1357633991933297.

33. Ackerman MJ, Filart R, Burgess LP, Lee I, Poropatich RK. Developing next-generation telehealth tools and technologies: patients, systems, and data perspectives. Telemed J E Health. 2010;16(1):93-5. Doi: 10.1089/tmj.2009.0153

34. Stanberry B. The legal and ethical aspects of telemedicine. 1: confidentiality and the patient's rights of access. J Telemed Telecare. 1997;3:179-87. Doi: 10.1258/1357633971931101.

35. Lustgarten SD, Colbow AJ. Ethical concerns for telemental health therapy amidst governmental surveillance. American Psychologist. 2017;72(2):159-70. Doi: 10.1037/a0040321.

36. Stanberry B. The legal and ethical aspects of telemedicine. 2: Data protection, security and European Law. J Telemed Telecare. 1998;4(1): 18-24. Doi: 10.1258/1357633981931236.

Table 1: Authors' framework to address the ethical issues pertaining to telemedicine practice, 2020

\begin{tabular}{|c|l|}
\hline Ethical concern & Recommendation \\
\hline $\begin{array}{c}\text { Informed consent } \\
\text { consent }\end{array}$ & $\begin{array}{l}\text { To be taken before every consultation. It can be } \\
\text { either verbal or electronic. Recording the act of } \\
\text { consent is preferred to prevent future litigation. }\end{array}$ \\
\hline $\begin{array}{c}\text { b. Referral } \\
\text { informed } \\
\text { consent }\end{array}$ & $\begin{array}{l}\text { The primary RMP is obligated to take written } \\
\text { informed consent from a patient before } \\
\text { consulting a specialist. The written consent } \\
\text { should be provided to the second RMP to whom } \\
\text { the patient is referred. This would safeguard } \\
\text { both the medical professionals and patient. }\end{array}$ \\
\hline $\begin{array}{l}\text { c. IT component of } \\
\text { i. end-to-end encryption for the protection of } \\
\text { privacy; } \\
\text { ii. a predetermined ti meframe for the } \\
\text { conservation of a } \\
\text { patient's data (including sensitive } \\
\text { information); } \\
\text { iii. telemedicine rules that incorporate the } \\
\text { recommendations of the Personal Data } \\
\text { Protection Act (pending) in the Guidelines; } \\
\text { and }\end{array}$ \\
\hline
\end{tabular}

\begin{tabular}{|c|c|}
\hline & $\begin{array}{l}\text { iv. a national health authority for the } \\
\text { development of an improvised IT } \\
\text { infrastructure that resolves many privacy } \\
\text { and security issues. }\end{array}$ \\
\hline Autonomy & $\begin{array}{l}\text { Increase users' literacy with respect to health } \\
\text { and digital technologies to promote informed } \\
\text { self-care. }\end{array}$ \\
\hline Standard of care & $\begin{array}{l}\text { The recommended treatment includes the } \\
\text { provision of counselling, certain drugs, and first } \\
\text { aid. } \\
\text { We propose establishing affiliations with local } \\
\text { healthcare centres to deal with emergency } \\
\text { situations. The creation of a single identity under } \\
\text { the National Digital Health Mission may facilitate } \\
\text { this. }\end{array}$ \\
\hline $\begin{array}{l}\text { Doctor-patient } \\
\text { relationship }\end{array}$ & $\begin{array}{l}\text { Train doctors and allied medical personnel in } \\
\text { social and communication skills that will } \\
\text { enhance doctor-patient relationships. } \\
\text { Additionally, offer the user health literacy and } \\
\text { education on the etiquettes of using } \\
\text { telemedicine services. }\end{array}$ \\
\hline Technical aspects & $\begin{array}{l}\text { The mode of consultation should be user- } \\
\text { friendly and multiple platforms on which to seek } \\
\text { healthcare facilities may be developed. }\end{array}$ \\
\hline Confidentiality & $\begin{array}{l}\text { Informed consent documentation must include } \\
\text { the name of the data holder and a } \\
\text { confidentiality clause for any agreement with } \\
\text { software developers. The same clause should be } \\
\text { added to the job descriptions and work } \\
\text { agreements of other staff engaged in the } \\
\text { provision of healthcare. It would be beneficial for } \\
\text { the Personal Data Protection Act (when it comes } \\
\text { into force) to provide a structural framework for } \\
\text { various online consumer services, ensure the } \\
\text { protection of the data, and set up authorities to } \\
\text { handle violations. More laws are required to } \\
\text { address the dispersal of information and health } \\
\text { records stored in hospitals when patients seek } \\
\text { them. }\end{array}$ \\
\hline Research & $\begin{array}{l}\text { Establish research guidelines pertaining to the } \\
\text { recording of patient data, reports, and other } \\
\text { documents. }\end{array}$ \\
\hline Insurance & $\begin{array}{l}\text { Include telemedicine services in insurance and } \\
\text { indemnity claims. }\end{array}$ \\
\hline
\end{tabular}

